PNL-4515

UC-41

\title{
Guidelines for the Calibration of Personnel Dosimeters
}

\author{
P. L. Roberson \\ K. L. Holbrook
}

January 1984

Prepared for the U.S. Department of Energy under Contract DE-AC06-76RLO 1830

Pacific Northwest Laboratory

Operated for the U.S. Department of Energy by Battelle Memorial Institute 


\title{
DISCLAIMER
}

This report was prepared as an account of work sponsored by an agency of the United States Government. Neither the United States Government nor any agency thereof, nor any of their employees, makes any warranty, express or implied, or assumes any legal liability or responsibility for the accuracy, completeness, or usefulness of any information, apparatus, product, or process disclosed, or represents that its use would not infringe privately owned rights. Reference herein to any specific commercial product, process, or service by trade name, trademark, manufacturer, or otherwise, does not necessarily constitute or imply its endorsement, recommendation, or favoring by the United States Government or any agency thereof. The views and opinions of authors expressed herein do not necessarily state or reflect those of the United States Government or any agency thereof.

\author{
PACIFIC NORTHWEST LABORATORY \\ operated by \\ BATTELLE \\ for the \\ UNITED STATES DEPARTMENT OF ENERGY \\ under Contract DE-AC06-76RLO 1830
}

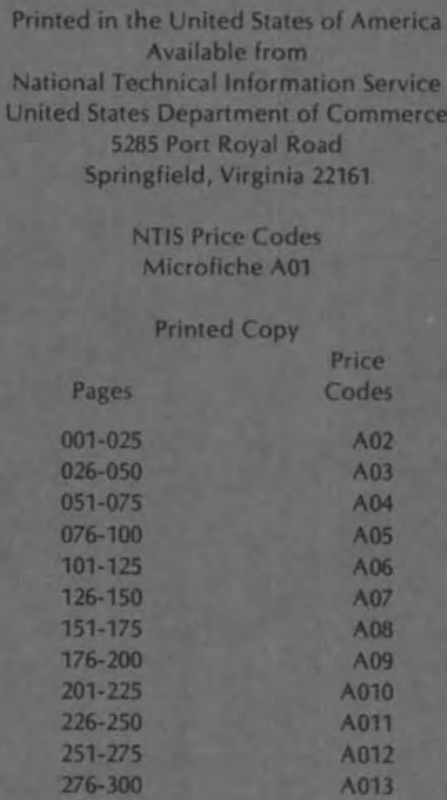


GUIDELINES FOR THE CALIBRATION

OF PERSONNEL DOSIMETERS

P. L. Roberson
K. L. Holbrook

January 1984

Prepared for

U.S. Department of Energy

under Contract DE-AC06-76RL0 1830

Pacific Northwest Laboratory

Operated for the U.S. Department of Energy

by Battelle Memorial Institute

(a) 265 El Dorado B7vd., No. 713 Webster, TX 77598 


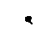

.

,

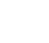




\section{PREFACE}

This work is part of the research project "Technical Guidelines for Personnel Dosimetry Calibrations" performed by the Pacific Northwest Laboratory for the Office of Nuclear Safety, Office of Environmental Protection, Safety and Emergency Preparedness, Department of Energy (DOE). The scope of the project is to develop guidelines for radiological calibrations of personnel dosimeters and radiation protection instruments used at DOE facilities. A voluntary testing program on the performance of DOE personnel dosimetry systems provided the data base to develop guidelines for the calibration of personnel dosimeters. 



\section{SUMMARY}

This guide describes minimum levels of acceptable performance for personnel dosimetry systems used at Department of Energy (DOE) facilities. The goal is to improve both the quality of radiological calibrations and the methods of comparing reported occupational doses between DOE facilities.

Reference calibration techniques are defined to help improve uniformity of dosimeter calibrations. A standard for evaluation of personnel dosimetry systems and recommended design parameters for personnel dosimeters are also included. Approximate intervals for the radiation energies for which these guidelines are appropriate are $15 \mathrm{keV}$ to $2 \mathrm{MeV}$ for photons; above $0.3 \mathrm{MeV}$ for beta particles; and $1 \mathrm{keV}$ to $2 \mathrm{MeV}$ for neutrons.

The procedures specified by the guidelines differ from those of ANSI N13.11-1983 in that they are designed to standardize and evaluate rather than test a personnel dosimetry system. The geometries of the calibration techniques follow those given in ANSI N13.11 as closely as practical.

An analysis of ANSI N13.11 was completed using performance evaluations of selected personnel dosimetry systems in use at DOE facilities. The results of this analysis were incorporated in the recommended calibration guidelines. The results are summarized below:

- The number of test sources and categories was inadequate. Recommended additions included a low-energy beta source, a second neutron source, and an x-ray/neutron mixture category.

- The performance algorithm was arbitrarily specified. It was modified to meet recommendations of the International Commission on Radiation Units and Measurements (Report 20) and the National Council on Radiation Protection and Measurements (Report No. 57).

- The beta-particle specifications were insufficient. Specification of the acceptable range of depth dose was required to improve standardization of calibrations. 
- The exposure-to-dose conversion factors for photons $\left(C_{x}\right.$ factors) did not match the calibration geometry; therefore, appropriate $C_{x}$ factors were used.

The recommendations for the design and use of personnel dosimetry systems that are included were based on the performance evaluations of selected DOE systems. Design features associated with superior dosimeter system performance are summarized. 
CONTENTS

PREFACE • • • •

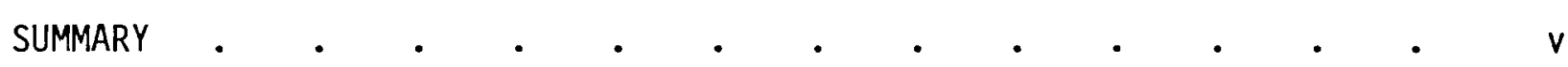

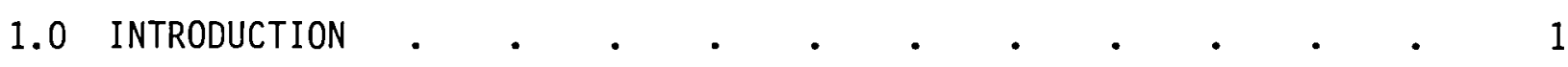

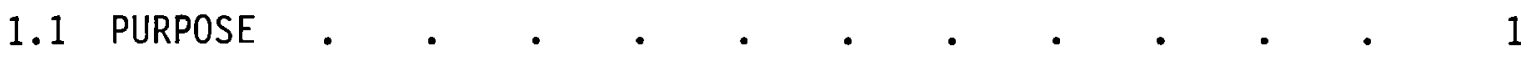

1.2 SCOPE $. \quad . \quad . \quad . \quad . \quad . \quad . \quad . \quad . \quad . \quad . \quad 1$

1.3 USE • . . . . . . . . . . . . . . 2

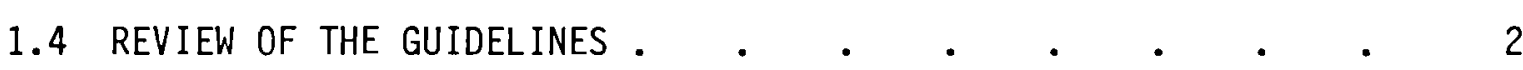

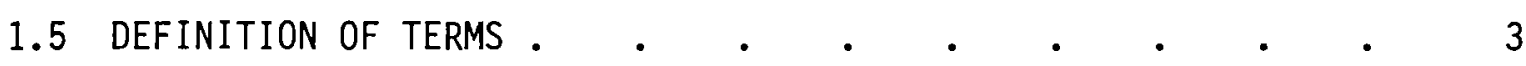

2.0 GUIDELINES FOR THE CALIBRATION OF PERSONNEL DOSIMETERS . . $\quad 5$

2.1 RADIATION SOURCES

2.2 CALIBRATION OF RADIATION FIELDS .

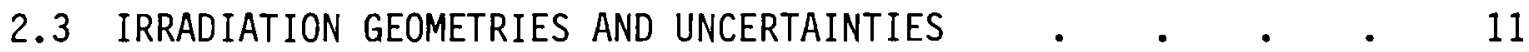

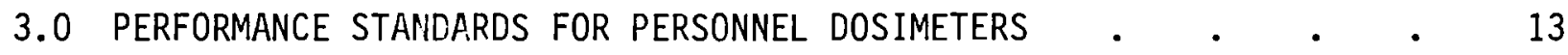

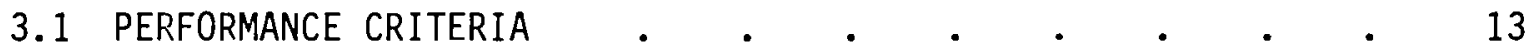

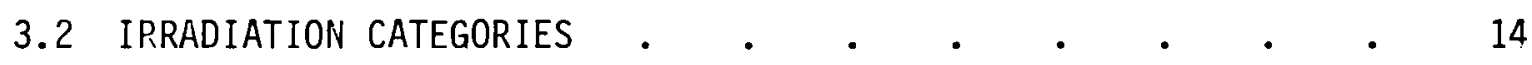

4.0 RECOMMENDATIONS FOR THE DESIGN AND USE OF PERSONNEL
DOSIMETRY SYSTEMS

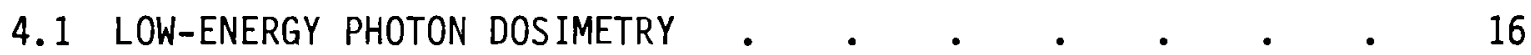

4.2 LOW-ENERGY BETA DOSIMETRY . . . . . . . . . . . 17

4.3 DOSIMETRY FOR MIXED BETA-PHOTON FIELDS • • • • • • • 18

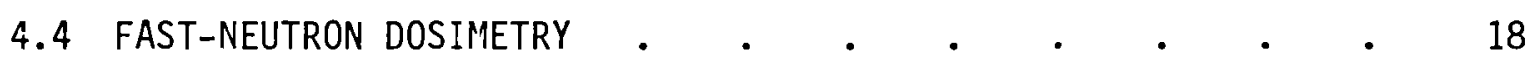

REFERENCES . 
APPENDIX A. CHOICE OF REFERENCE CALIBRATION SOURCES - $\quad$ - $\quad$ - $\quad$ A. 1

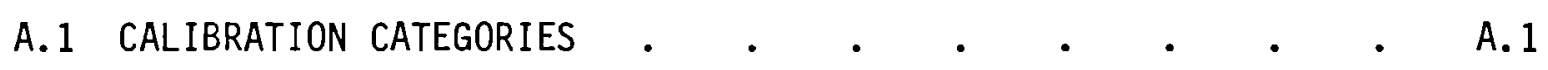

A.2 ADDITIONAL SPECIFICATIONS FOR BETA CALIBRATIONS • • • A.

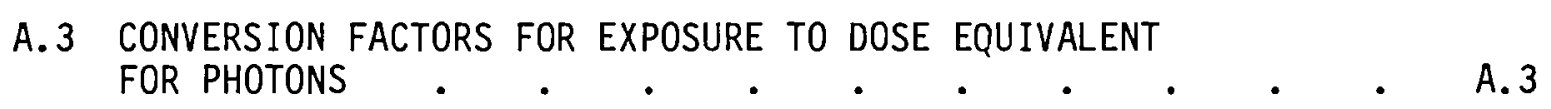

APPENDIX B. DERIVATION OF PERFORMANCE CRITERIA $\quad \cdot \quad \cdot \quad \cdot \quad \cdot \quad \cdot \quad$ B. 1

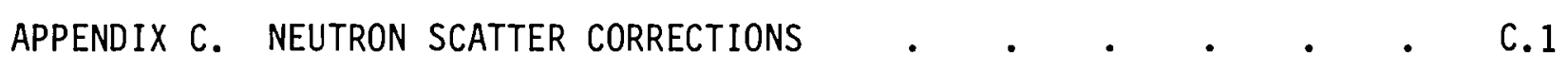

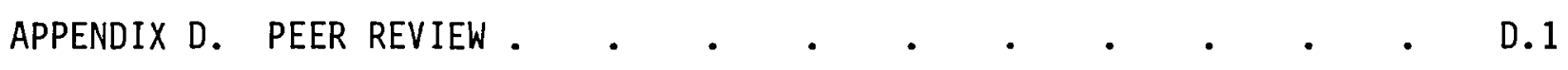




\section{TABLES}

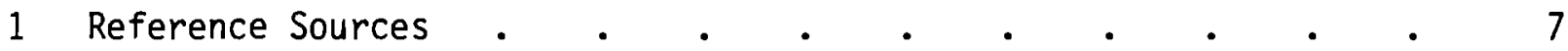

2 Exposure-to-Dose-Equivalent Conversion Factors for Photons . $\quad 9$

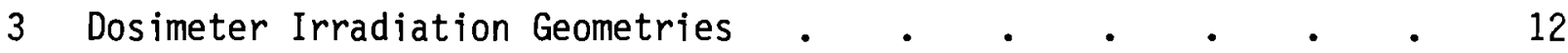

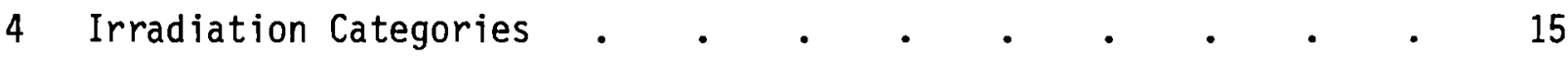




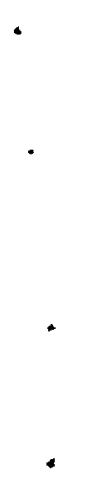




\subsection{INTRODUCTION}

This guide defines a set of reference calibrations to help establish a uniform approach to personnel dosimetry and a standard by which personnel dosimetry systems can be evaluated. The guidelines include calibration techniques, performance criteria, and recommended design parameters for personnel dosimeters.

The performance criteria are based on recommendations of the International Commission on Radiation Units and Measurements (ICRU) and National Council on Radiation Protection and Measurements (NCRP) and are closely related to the American National Standard, "Criteria for Testing Personnel Dosimetry Performance", ANSI N13.11-1983 (ANSI 1983). The procedures for the guidelines differ from those of ANSI N13.11 in that they are used to evaluate rather than test a personnel dosimetry system. Most of the irradiation techniques are consistent with ANSI N13.11 although additional calibration points were added for completeness and flexibility.

The guidelines for the design and use of personnel dosimeters are based on the performance data of Department of Energy (DOE) dosimetry systems summarized in "Performance Comparisons of Selected Personnel Dosimetry Systems in use at Department of Energy Facilities" (Roberson et al. 1983). The guidelines encompass existing dosimeter system designs and allow for future innovation in personnel dosimetry. Design features associated with superior dosimeter system performance are summarized.

\subsection{PURPOSE}

The purpose of the guidelines is to describe minimum levels of acceptable performance and to enhance comparability of reported occupational doses between DOE facilities.

\subsection{SCOPE}

This guide includes technical information and procedures required to establish a minimum level of performance and to encourage high-quality uniform dosimetry practices for DOE facilities. The focus is uniform response through 
improved calibration techniques. Recommendations for the design and handling of dosimeters are included where they materially affect dosimetry system performance.

The guidelines apply to whole-body personnel dosimetry systems used to estimate dose equivalent for the permanent record. Dosimetry performed for health protection under normal conditions and accident conditions is included.

These guidelines apply for specific energy intervals. Approximate intervals are $15 \mathrm{keV}$ to $2 \mathrm{MeV}$ for photons; above $0.3 \mathrm{MeV}$ for beta particles; and $1 \mathrm{keV}$ to $2 \mathrm{MeV}$ for neutrons.

\section{$1.3 \underline{\text { USE }}$}

Energies, source specifications, and standard irradiation geometries for the recommended reference calibration points are given in Section 2.0. The performance criteria defined in subsection 3.1 can be used to determine dosimeter performance for the reference calibration points. Where the performance criteria cannot be satisfied, the dosimeter design and dose evaluation procedures should be reviewed. Section 4.0 contains recommended guidelines for effective dosimeter designs and dose evaluation methods.

Calibrations used for the evaluation of occupational doses or dose equivalents may differ from the reference calibrations. Where differences exist, the cosimeter response-per-unit dose (or dose equivalent) of the optimal calibration for the occupational environment (field calibration) should be determined relative to a reference calibration.

A facility should be excluded from compliance with certain portions of the guidelines if a technical basis is demonstrated. Compliance should not be required for radiation types or energies not present in a specific occupational environment.

\subsection{REVIEW OF THE GUIDELINES}

The guidelines shall be reviewed and updated when considered necessary by the DOE. Technological advances in both beta and neutron personnel dosimetry practices may allow strengthening of the performance specifications. In addition, it may be desirable to broaden the scope of the guidelines. 


\subsection{DEFINITION OF TERMS}

The definition for many of the terms used in this guide are given below:

Absorbed Dose (D) - The energy absorbed per unit mass at a specified point.

The special unit is the rad. The SI unit is the gray (Gy).

$1 \mathrm{~Gy}=100 \mathrm{rad}$.

Dose Equivalent (H) - The product of the absorbed dose (D), the quality factor $(Q)$, and any other modifying factors. The special unit is the rem. When $D$ is expressed in Gy, $H$ is in Sieverts (Sv). $1 \mathrm{~Sv}=100 \mathrm{rem}$.

Shallow and Deep Absorbed Dose ( $\mathrm{D}_{s}$ and $\mathrm{D}_{\mathrm{d}}$ ) or Dose Equivalent $\left(\mathrm{H}_{\mathrm{S}}\right.$ and $\mathrm{H}_{\mathrm{d}}$ ) - The absorbed dose or dose equivalent at the respective depths of $0.007 \mathrm{~cm}$ and $1.0 \mathrm{~cm}$ in a material of specified geometry and composition.

Exposure-to-Dose-Equivalent Conversion Factor for Photons $\left(C_{x}\right)$ - The numerical quantity that relates the exposure in air to the dose equivalent at a specified depth in a material of specified geometry and composition. The $C_{x}$ factors change as a function of photon energy, material geometry (e.g. sphere, slab, or torso), and composition (e.g. tissue-equivalent plastic, soft tissue ignoring trace elements, or soft tissue including trace elements).

Protection Dosimetry - Routine measurements and estimation of the dose equivalent for the purpose of determining and controlling the dose equivalent received by radiation workers.

Accident Dosimetry - Determination of high levels of absorbed dose resulting from uncontrolled conditions.

Dosimeter - A combination of absorbers and radiation-sensitive element or elements packaged to provide a cumulative record of absorbed dose or dose equivalent received when worn by an individual.

Irradiation Category - Each type and energy (or mixture) of radiation for which performance criteria are given.

Performance Quotient $\left(P_{i}\right)$ - The fractional difference between the determined and delivered absorbed dose or dose equivalent for the $i^{\text {th }}$ dosimeter 


$$
P_{i} \equiv \frac{\left.\left[X_{i} \text { (determined) }-x_{i} \text { (de } 1 \text { ivered }\right)\right]}{X_{i} \text { (delivered) }}
$$

where $D_{d}, H_{s}$, or $H_{d}$ can be inserted for $x$.

Bias (B) - The average of the performance quotients, $P_{i}$, for $n$ dosimeters, for a specific irradiation category and depth,

$$
B \equiv \frac{1}{n} \sum_{i=1}^{n} P_{i} .
$$

Standard Deviation (S) - The standard deviation of the performance quotients, $P_{i}$, calculated for $n$ dosimeters for a specified irradiation category and depth,

$$
S \equiv\left[\frac{{ }_{i=1}^{n}\left(P_{i}-B\right)^{2}}{n-1}\right]^{\frac{1}{2}}
$$

Free-Field Dose Equivalent - The dose equivalent assigned for neutron irradiations as if performed in free space. To calculate free-field dose equivalent, correct for background due to air and room scattering and for source asymmetry (Schwartz and Eisenhauer 1982). 


\subsection{GUIDELINES FOR THE CALIBRATION OF PERSONNEL DOSIMETERS}

The specified calibrations represent the minimum necessary to ensure adequate performance for a multipurpose personnel dosimetry system. Most of the irradiation categories specified in ANSI N13.11 are included. The range of dose equivalents for each category was taken from ANSI N13.11.

The geometries specified for the calibrations follow those given in ANSI N13.11 as closely as practical. Major differences are: 1) the specified exposure-to-dose-equivalent conversion factors for photons $\left(C_{x}\right)$ are more appropriate for the calibration geometry; and 2) the specifications for the beta source calibration are more complete. A more comprehensive discussion is presented in Appendix $A$.

\subsection{RADIATION SOURCES}

The response of the personnel dosimetry system shall be determined using the following sources:

- a ${ }^{137}$ Cs gamma-ray source

- The dose rate at the shallow tissue depth $(0.007 \mathrm{~cm})$ should be maintained within $5 \%$ of the dose rate at the deep depth $(1 \mathrm{~cm})$.

- $x$-ray machine(s) producing continuous spectra using the U.S. National Bureau of Standards (NBS) techniques (NBS 1981a) and nearly monoenergetic techniques

- Low-energy, nearly monoenergetic photon beams (15 to $20 \mathrm{keV}, 55$ to $65 \mathrm{keV}$ ) apply for work environments containing plutonium.

- A ${ }^{241}$ Am source may be substituted for the 55 to $65 \mathrm{keV}$ nearly monoenergetic source.

- The k-fluorescent $x$-ray technique is described by Larson, Meyers and Roesch (1954), Kathren, Rising and Larson (1971), and the International Organization for Standardization (ISO 1979).

- a sealed ${ }^{90} \mathrm{Sr} /{ }^{90} \mathrm{Y}$ beta particle source with a $100 \mathrm{mg} / \mathrm{cm}^{2}$ filter (nomina 1 ) 
- The in-phantom dose rate at $100 \mathrm{mg} / \mathrm{cm}^{2}$ divided by the dose rate at $7 \mathrm{mg} / \mathrm{cm}^{2}$ should be $1.01 \pm 0.05$.

- The in-phantom dose rate at $1000 \mathrm{mg} / \mathrm{cm}^{2}$ should be less than $1 \%$ of the dose rate at $7 \mathrm{mg} / \mathrm{cm}^{2}$.

- a ${ }^{204} \mathrm{Tl}$ source filtered by $50 \mathrm{mg} / \mathrm{cm}^{2}$ (nominal)

- The in-phantom dose rate at $20 \mathrm{mg} / \mathrm{cm}^{2}$ divided by the in-phantom dose rate at $7 \mathrm{mg} / \mathrm{cm}^{2}$ should be $0.80 \pm 0.05$.

- a natural or depleted uranium slab

- In-phantom dose rates at $7 \mathrm{mg} / \mathrm{cm}^{2}$ and $100 \mathrm{mg} / \mathrm{cm}^{2}$ should be measured.

- a ${ }^{252} \mathrm{Cf}$ neutron source used unmoderated and moderated by $15 \mathrm{~cm}$ of $\mathrm{D}_{2} 0$ (Schwartz and Eisenhauer 1980)

- Use of the unmoderated source is recommended to obtain a relative response to the moderated source.

\subsection{CALIBRATION OF RADIATION FIELDS}

The calibration procedures used for the radiation fields shall be referenced to source fields standardized by NBS and be consistent with accepted national standards and practices. Reference class instruments, as defined in Special Publication 603 (NBS 1981b), or sealed radioactive sources should be used. A list of calibration services offered by NBS is included in Special Publication 250 (NBS 1981a).

The list of reference sources is given in Table 1 . The rationale for selecting the reference calibration sources is discussed in Appendix A.1. Requirements for beta calibration spectra are included in Appendix A.2.

\subsubsection{Photon Fields}

Photon radiation fields are calibrated in terms of exposure in free air. For the NBS techniques and the ${ }^{137}$ Cs source, a reference class ionization chamber calibrated by NBS for the particular techniques specified in Table 1 is preferred. Calibrate other photon sources using a free-air ionization chamber 
TABLE 1. Reference Sources

Source

Low-Energy Photons

NBS Filtered Techniques (a)

M30 (LG) ${ }^{(b)}$

S60 (MFC) ${ }^{(b)}$

M150 (MFI) ${ }^{(b)}$

H150 (HFG)

Monoenergetic (c)

$241_{A m}(c)$

High-Energy Photons

${ }^{137_{\mathrm{Cs}}}$ (b)

Beta Particles

${ }^{204} \mathrm{~T} 1$

${ }^{90} \mathrm{Sr} /{ }^{90} Y$ (filtered) ${ }^{(b)}$

Uranium slab
Energy

$20 \mathrm{keV}$ (average)

$36 \mathrm{keV}$ (average)

$70 \mathrm{keV}$ (average)

$120 \mathrm{keV}$ (effective)

15 to $20 \mathrm{keV}$

55 to $65 \mathrm{keV}$

$59 \mathrm{keV}$

$662 \mathrm{keV}$

$0.76 \mathrm{MeV}$ (maximum)

2.3 MeV (maximum)

2.3 MeV (maximum)

Neutron

$$
\begin{aligned}
& { }^{252} \mathrm{Cf} \text { (Moderated) } \\
& { }^{252} \mathrm{Cf} \text { (Unmoderated) }
\end{aligned}
$$

(a) NBS Special Publication 250, Appendix (NBS 1981a).

(b) These sources are specified in ANSI N13.11.

(c) These sources were included specifically for work environments containing plutonium.

(d) Moderated by $15 \mathrm{~cm}$ of $\mathrm{D}_{2} \mathrm{O}$ (Schwartz and Eisenhauer 1980). 
or an NBS-calibrated, high-quality ionization chamber with a known slowly varying energy dependence. If a free-air ionization chamber is used, check its operation using a beam for which NBS referenced calibration is obtained.

Calculate the dose equivalent assigned to exposed dosimeters using the exposure-to-dose-equivalent conversion factors $\left(C_{x}\right)$ listed in Table 2 . The rationale used for choosing this particular set of $C_{x}$ is given in Appendix A.3. Dose equivalent for sealed source irradiations is calculated:

$$
H=c_{x} \dot{x}_{a \text { ir }} t
$$

where $\dot{x}_{a i r}$ is the exposure rate in air calibrated using the above procedure, and $t$ is the irradiation time. For exposures referenced to an unsealed monitor ionization chamber,

$$
H=C_{x} T M C_{T P}
$$

where $T$ is the exposure per charge factor for the monitor chamber at the standard temperature and pressure; $M$ is the reading of the monitor chamber in units of charge; and $C_{T P}$ is the temperature and pressure correction factor for the monitor chamber.

\subsubsection{Beta-Particle Fields}

Beta-particle fields are calibrated in terms of absorbed dose at a tissue depth of $0.007 \mathrm{~g} / \mathrm{cm}^{2}$ using a thin-window, tissue-equivalent extrapolation chamber with the appropriate tissue-equivalent buildup thickness in front of the window. Calibrate the extrapolation chamber using a beta-particle source with a calibration referenced to NBS standards.

Calibration depths used for beta irradiations range from a few tenths of milligrams per square centimeter to $7 \mathrm{mg} / \mathrm{cm}^{2}$. If a source has been calibrated at depths other than $7 \mathrm{mg} / \mathrm{cm}^{2}$, measurement of a transmission factor is required. Measure the transmission factor with a thin-window ionization chamber or extrapolation chamber. Position the chamber with its effective center at the calibrated point; measure at the depth of calibration and at 
TABLE 2. Exposure-to-Dose-Equivalent Conversion Factors for Photons (a) NBS Filtered $X$-ray Techniques

Technique

M30

$\mathrm{S} 60$

M150

H150
Conversion Factors, rem/R Shallow $(0.007 \mathrm{~cm})$ Deep $(1.0 \mathrm{~cm})$

1.08

1.15

1.41

1.41

0.45

1.07

1.47

1.41

K-Fluorescent $X$-ray Techniques

Energy, keV

$\begin{array}{rll}16 & 1.08 & 0.38 \\ 24 & 1.07 & 0.74 \\ 34 & 1.07 & 0.99 \\ 43 & 1.28 & 1.30 \\ 58 & 1.47 & 1.54 \\ 78 & 1.61 & 1.72 \\ 100 & 1.59 & 1.74\end{array}$

${ }^{137} \mathrm{Cs}$

662

- (b) $^{-1}$

1.03

(a) Data taken from Yoder et al. (1979).

(b) This value is dependent on source geometry and should be measured. 
$7 \mathrm{mg} / \mathrm{cm}^{2}$. If material must be added to reach the required measurement depth, place it in contact with the surface of the chamber. The total material thickness should be within $\pm 0.5 \mathrm{mg} / \mathrm{cm}^{2}$ of the nominal measurement depth. The transmission factor is calculated as follows:

$$
c_{\text {trans }}=\frac{\dot{x}\left(7 \mathrm{mg} / \mathrm{cm}^{2}\right)}{\dot{x}(\mathrm{~d})}
$$

where $X$ is the relative chamber signal, corrected for temperature and pressure, and $d$ is the original calibration depth.

The dose equivalent assigned to exposed dosimeters is calculated using

$$
H=\dot{D}_{t}(d) \cdot t \cdot Q \cdot C_{\text {trans }}
$$

where $\dot{D}_{t}$ is the absorbed dose rate at the calibration depth $d, t$ is the time, and $Q$ is the quality factor ( $1 \mathrm{~Sv} / \mathrm{Gy}$ ).

\subsubsection{Neutron Fields}

The ${ }^{252} \mathrm{Cf}$ source(s) are calibrated in terms of neutron emission rate by NBS or other qualified laboratory using equipment and techniques referenced to NBS standards. Procedures for calculating the dose equivalent for exposed dosimeters shall follow NBS Special Publication 633, "Procedures for Calibrating Neutron Personnel Dosimeters" (Schwartz and Eisenhauer 1982). In this publication the free-field dose equivalent (mrem) for unmoderated exposures is defined by:

$$
H=\frac{N \times C_{U N} \times t \times 3600}{4 \pi r^{2}}
$$

where $N$ is the neutron emission rate $(n / \mathrm{sec}), C_{U N}$ is the dose-equivalent conversion factor for unmoderated ${ }^{252} \mathrm{Cf}\left(3.33 \times 10^{-5} \mathrm{mrem} \mathrm{cm}{ }^{2}\right), t$ is the time (h), 3600 is the number of seconds in an hour, and $r$ is the calibration distance (from the source center to the front face of the phantom, cm). For the moderated source, 


$$
H=\frac{N \times C_{M} \times t \times 3600 \times 0.89}{4 \pi r^{2}}
$$

where $C_{M}$ is the dose-equivalent conversion factor for moderated ${ }^{252} \mathrm{Cf}(9.0 \mathrm{x}$ $\left.10^{-6} \mathrm{mrem} \mathrm{cm}^{2}\right)$, and the 0.89 allows for the loss of neutrons that are moderated below the cadmium cutoff.

Corrections must be applied to the dosimeter readings for air scattering, room return, and source scattering. These techniques are described in Special Publication 633. Example calculations are provided in Appendix C.

Measure the photon component for each irradiation geometry. Unmoderated ${ }^{252}$ Cf irradiations probably have a greater variation of photon component than the moderated irradiations due to greater relative differences in source filtration. Typical values are $7 \%$ of the neutron dose equivalent for unmoderated irradiations (Plato and Hudson 1980) and 18\% for moderated irradiations (McDonald et a1. 1983a).

\subsection{IRRADIATION GEOMETRIES AND UNCERTAINTIES}

The dosimeters are irradiated using a phantom backing, except for oncontact uranium calibrations. Recommended phantoms are methylmethacrylate slabs measuring $30 \mathrm{~cm} \times 30 \mathrm{~cm} \times 15 \mathrm{~cm}$ for photon calibrations, $30 \mathrm{~cm} \times 30 \mathrm{~cm} \times$ $\geq 5 \mathrm{~cm}$ for beta-particle calibrations, and $40 \mathrm{~cm} \times 40 \mathrm{~cm} \times 15 \mathrm{~cm}$ for neutron calibrations. Attach the dosimeters to the surface of the phantom facing the source. For collimated beams, position the central beam axis perpendicular to and passing through the center of the front face of the phantom. For uncollimated beams, position the center of the front face of the phantom perpendicular to a radial line from the source center. Mount dosimeters with the sensitive elements within the central $15 \mathrm{~cm} \times 15 \mathrm{~cm}$ area of the phantom for photon and beta-particle irradiations and within the central $20 \mathrm{~cm} \times 20 \mathrm{~cm}$ area for neutron irradiations. The point of calibration should coincide with the center of the front face of the phantom. The irradiation geometries are surmarized in Table 3. 
TABLE 3. Dosimeter Irradiation Geometries

\begin{tabular}{|c|c|c|c|}
\hline Source Type & Phantom Size & Distance, $\mathrm{cm}^{(\mathrm{a})}$ & Useful Area ${ }^{(b)}$ \\
\hline $\begin{array}{l}\text { Photon Sources } \\
137 \mathrm{Cs}\end{array}$ & $30 \mathrm{~cm} \times 30 \mathrm{~cm} \times 15 \mathrm{~cm}$ & $>100$ & $15 \mathrm{~cm} \times 15 \mathrm{~cm}$ \\
\hline NBS Filtered $x$ rays & & $\geq 100$ & \\
\hline $\begin{array}{l}\text { Monoenergetic } \\
x \text { rays }\end{array}$ & & $\geq 50$ & \\
\hline Beta Source & & & \\
\hline${ }^{90} \mathrm{Sr} /{ }^{90} \mathrm{Y}$ & $30 \mathrm{~cm} \times 30 \mathrm{~cm} \times \geq 5 \mathrm{~cm}$ & $\geq 30$ & $15 \mathrm{~cm} \times 15 \mathrm{~cm}$ \\
\hline${ }^{204} \mathrm{TI}$ & $30 \mathrm{~cm} \times 30 \mathrm{~cm} \times \geq 5 \mathrm{~cm}$ & $30-50$ & $15 \mathrm{~cm} \times 15 \mathrm{~cm}$ \\
\hline Uranium slab & - & On contact & - \\
\hline Neutron Sources & $40 \mathrm{~cm} \times 40 \mathrm{~cm} \times 15 \mathrm{~cm}$ & $\geq 50$ & $20 \mathrm{~cm} \times 20 \mathrm{~cm}$ \\
\hline
\end{tabular}

(a) Distance from the source center to the front face of the phantom.

(b) Position dosimeters with the sensitive elements within the listed area centered on the front face of the phantom. The useful area may be smaller if dose non-uniformity results in the total uncertainty exceeding $\pm 5 \%$.

The uncertainty in the assigned dose equivalent should not exceed $\pm 5 \%$, excluding uncertainties in the dose-equivalent conversion factors and the photon component of the neutron irradiations. For photon and beta-particle irradiations, the scatter from the irradiation room surfaces and the source and phantom support hardware should contribute $2 \%$ or less uncertainty in the assigned dose equivalent. If several dosimeters are irradiated simultaneously, take precautions to keep the mutual interference much smaller than the $5 \%$ uncertainty in the assigned dose equivalent. 


\subsection{PERFORMANCE STANDARDS FOR PERSONNEL DOSIMETERS}

\section{I PERFORMANCE CRITERIA}

The standard of performance is based on recommendations in ICRU Report 20 (ICRU 1971) and NCRP Report No. 57 (NCRP 1978a) specifying a 30\% limit on the uncertainty of the maximum dose equivalent in the vicinity of the maximum permissible levels. Due to the small observed variance in uncertainty over the typical range of dose equivalent (Roberson et al. 1983), this limit can also apply at lower values. The following performance criterion approximately represents the requirement that $95 \%$ of the annual reported doses be within $30 \%$ of the conventionally true dose equivalent, assuming a dosimeter exchange rate of four times per year and approximately uniform occupational exposures (see Appendix B):

$$
|B|+S \leq 0.3
$$

To allow for statistical measurement errors during the evaluation of personnel dosimetry systems, the tolerance level can be increased and the number of sample dosimeters specified as a function of the standard deviation. The recommended algorithm for the evaluation of personnel dosimetry systems is:

$$
|B|+S \leq 0.35 \text { for a sample of } N \text { dosimeters }
$$

where the minimum number of dosimeters recommended per calibration point is a

\begin{tabular}{|c|c|}
\hline$S$ & $\mathrm{~N}$ \\
\hline$\leq 0.10$ & 15 \\
\hline $0.1 \overline{1}-0.15$ & 30 \\
\hline $\begin{array}{r}0.16-0.24 \\
>0.25\end{array}$ & $\begin{array}{r}60 \\
120\end{array}$ \\
\hline
\end{tabular}
function of the standard deviation (evaluated for a zero bias):

Test results for two of the sources listed in Table 1 cannot be expected to meet the above performance requirements due to technological or practical 
limitations of current dosimeter designs. The recommended algorithm for the ${ }^{204} \mathrm{Tl}$ test is:

$$
|\mathrm{B}|>0.5
$$

It is recommended that no test algorithm be applied for the unmoderated ${ }^{252} \mathrm{Cf}$ test.

The standard deviation is composed of dosimeter variations present in a batch of dosimeters read sequentially and of the long-term variability of the calibration plus readout process. The summed standard deviation can be determined by splitting the evaluation over a period of time, such as the three-month interval used in ANSI N13.11, or by monitoring the variability using routine quality control procedures and incorporating it into the total standard deviation (using the square root of the sum of the squares).

\subsection{IRRADIATION CATEGORIES}

Use the categories listed in Table 4 and the performance criteria in Equations (3.2), (3.3), and (3.4) for the evaluation of personnel dosimetry systems. Special cases are listed below:

1. The nearly monoenergetic $x$-ray or ${ }^{241}$ Am source evaluation is intended for use in facilities handling plutonium. The ${ }^{241} \mathrm{Am}$ source may be substituted for the 55 to $65 \mathrm{keV}$ nearly monoenergetic source. Perform the I \& IV mixture using one of these sources.

2. The ${ }^{204} \mathrm{Tl}$ evaluation may use the performance algorithm in Equation (3.4) instead of in Equation (3.2).

3. Use of a performance algorithm is not required for the unmoderated ${ }^{252} \mathrm{Cf}$ evaluation. It is sufficient to relate the dosimeter response for the unmoderated and the moderated ${ }^{252} \mathrm{Cf}$ sources. Mixture categories use the moderated source.

It is recommended that an evaluation of the personnel dosimetry system be conducted at two-year intervals. 


\section{TABLE 4. Irradiation Categories}

\section{Category}

I. Low-Energy Photons (X Ray),

Accident Dosimetry

NBS Filter (a) Technique

$$
\text { M150 }
$$

11. High-Energy Photons

Accident Dosimetry ${ }^{137}$ Cs (d)

111. Low-Energy Photons (X Ray)

NBS Filtered Techniques

\begin{tabular}{|c|c|}
\hline sfo (a) & \\
\hline $\begin{array}{l}S 60 \\
M 150\end{array}$ (a) & \\
\hline H150 & \\
\hline tonoenergetic & \\
\hline $\begin{array}{l}\text { Monoenergetic } \\
241_{\mathrm{Am}}\end{array}$ & \\
\hline
\end{tabular}

IV. High-Energy Photons

V. Beta Particles

$$
{ }^{90}{ }^{\mathrm{Sr} /}{ }^{90} \mathrm{Y} \text { (Filtered) (a) }
$$
VI. Neytrion
252 Cf (Moderated) (d)

\begin{tabular}{|c|c|c|}
\hline $\begin{array}{l}\text { III. \& IV. (a) } \\
\text { III. \& V. (a) } \\
\text { IV. \& V. (f) } \\
\text { III. \& VI. (a) } \\
\text { IV. \& VI. (a) }\end{array}$ & one energy from each category & $\begin{array}{l}0.03 \text { to } 5 \\
0.2 \text { to } 5 \\
0.2 \text { to } 5 \\
0.15 \text { to } 5 \\
0.15 \text { to } 5\end{array}$ \\
\hline
\end{tabular}

VII. Mixtures
10 to 500

10 to 500

0.03 to 10
$20 \mathrm{keV}$ (average)
$36 \mathrm{keV}$ (average)
$70 \mathrm{keV}$ (average)
$120 \mathrm{keV}$ (effective)
15 to $20 \mathrm{keV}$
55 to $65 \mathrm{keV}$
$59 \mathrm{keV}$

$662 \mathrm{keV}$

0.03 to 10

$0.76 \mathrm{MeV}$ (maximum)

$2.3 \mathrm{MeV}$ (maximum)

$2.3 \mathrm{MeV}$ (maximum)
Dose Equivalent

Range, rem

(a) This category or a subset of this category is specified in ANSI N13.11.

(b) These sources were included specifically for work environments containing plutonium. The ${ }^{241}$ Am source may replace the 55 to $65 \mathrm{keV}$ nearly monoenergetic source.

(c) A modified performance algorithm is recommended. Do not use in mixture category.

(d) Moderated by $15 \mathrm{~cm}$ of $\mathrm{D}_{2} \mathrm{O}$ (Schwartz and Eisenhauer 1980).

(e) Reference source only. Do not use in mixture category. (f) For 249 rk environments containing plutonium, use the nearly monoenergetic
or 24 sources. 


\subsection{RECOMMENDATIONS FOR THE DESIGN AND USE OF PERSONNEL DOSIMETRY SYSTEMS}

Performance evaluations of personnel dosimetry systems in use at selected DOE facilities indicated several design deficiencies that affected dosimeter performance (Roberson et a1. 1983; McDonald et al. 1983b). Common problems included energy-dependence at low photon energies, difficulties in measuring low-energy beta particles, and high variability of reported neutron doses. Superior dosimeter design features or analytical methods were identified in some instances; these are summarized for each irradiation category.

\subsection{LOW-ENERGY PHOTON DOSIMETRY}

The dosimeter designs that were evaluated utilized film or thermoluminescent (TL) dosimeters as the sensitive element for photon dose. Most of the $T L$ dosimeters and both of the $\mathrm{film}$ dosimeters overresponded to low-energy photon fields. These participants could not successfully calibrate to the NBS mediumfiltered $x$-ray techniques provided. Much of the difficulty in recalibrating the $\mathrm{TL}$ dosimeters was due to interdependencies between the photon and beta dose determinations; any change to improve the $x$-ray response was detrimental to beta performance. It is recommended that the shallow dose from betas and photons be calculated independently, if feasible.

Based on the results of the intercomparison, it is recommended that film dosimetry be phased out for monitoring in low-energy photon fields. Film response must be interpreted as a function of delivered dose and photon energy. The inherent energy dependence for most TL phosphors was less severe than the inherent energy dependence of film emulsions. The popular TL phosphors respond linearly for dose levels commonly encountered in personnel monitoring. The net effect is lower overall uncertainty in reported dose for TL dosimeters. Film dosimetry is viable for monitoring low-energy photon dose only when the occupational field environment is known precisely for each worker. In the intercomparison $x$-ray categories, film performance was generally worse than the poorest performance of the TL dosimeters. 
It is recommended that variable-calibration photon dosimeters be used for monitoring low-energy photons. Markedly superior performance was achieved by dosimetry systems using TL element response ratios to vary the algorithm as a function of photon energy. The overresponse of the TL material was corrected to yield a rem response using the appropriate $x$-ray calibration techniques. However, a poorly designed algorithm can result in high dosimeter variability and poor interpretation of reported doses. Check the algorithm thoroughly using the calibration techniques specified.

\subsection{LOW-ENERGY BETA DOSIMETRY}

The difficulties of using conventional thick TL dosimeter elements to monitor low-energy beta particles have been well documented (Gesell et al. 1979). Dosimeter elements respond proportional to the average dose over the thickness of the TL or film dosimeter. Commercially available $0.89 \mathrm{~mm}$ (35 mil) LiF chips have a density thickness of $230 \mathrm{mg} / \mathrm{cm}^{2}$. Since the depth of interest for the shallow-dose determination is $7 \mathrm{mg} / \mathrm{cm}^{2}$, significant errors can result for low-energy beta measurements. The dosimeter energy dependence is further degraded by adding material over the shallow-dose sensitive element. The performance of $\mathrm{film}$ dosimeters was poor, but better than the performance of $T L$ dosimeters using the $230 \mathrm{mg} / \mathrm{cm}^{2} \mathrm{LiF}$ chips. The performance evaluation of the beta dosimeters for selected DOE facilities indicated that only one of eleven laboratories could comply with the guideline for the beta category given in Section 3. Beta-dose determinations are further confused by the lack of a standard calibration geometry, as discussed in Appendix A.2.

Use of the minimum element thickness and the minimum necessary material thickness covering the shallow-dose element is recommended. The most successful DOE dosimeter design for monitoring low-energy beta particles utilized a sensitive $T L$ element $15 \mathrm{mg} / \mathrm{cm}^{2}$ in thickness, covered by $25 \mathrm{mg} / \mathrm{cm}^{2}$ of 10 w atomic number material. Where the use of ultra-thin sensitive elements is not practical, beta energy dependence can be improved by determining an effective energy and correcting the reported shallow dose. This method generally decreases dosimeter precision and may not be applicable for all beta dosimeter 
designs. Immediate improvement in many designs can be realized by decreasing the amount of material overlying the sensitive element.

\subsection{DOSIMETRY FOR MIXED BETA-PHOTON FIELDS}

Insufficient attenuation over the element used to evaluate dose at $1 \mathrm{~cm}$ resulted in misinterpretation of the deep dose from ${ }^{90} \mathrm{Sr} /{ }^{90} \mathrm{Y}$ irradiations and mixed ${ }^{90} \mathrm{Sr} /{ }^{90} \mathrm{Y}_{-}{ }^{137} \mathrm{Cs}$ fields. A filter thickness of at least $500 \mathrm{mg} / \mathrm{cm}^{2}$ is recommended to eliminate the ${ }^{90} Y$ component. The addition of a low atomic number material, such as plastic, over the deep-dose element will eliminate spurious dose indications from betas without adversely affecting the response to photons.

\subsection{FAST-NEUTRON DOSIMETRY}

Calibration techniques were identified as the primary source of bias in intercomparisons of neutron personnel dosimeters. It is recommended that scatter conditions in each facility be evaluated so that appropriate corrections can be applied to the calculated dose equivalents. A brief discussion of scatter calculations is given in Appendix $C$. Additional information may be found in NBS Special Publication 633 "Procedure for Calibrating Neutron Personnel Dosimeters" (Schwartz and Eisenhauer 1982).

A few TL albedo dosimeters displayed large standard deviations due to large variabilities in chip sensitivity factors. In such cases, it is recommended that individualized calibration factors be developed to compensate for varying $T L$ dosimeter sensitivities. Alternatively, tight screening of $T L$ elements or batching of dosimeters may be used. 


\section{REFERENCES}

American National Standards Institute (ANSI). 1983. American National Standard, Criteria for Testing Personnel Dosimetry Performance. ANSI N13.111983, New York, New York.

Dimbylow, P. J. and T. M. Francis. 1979. A Calculation of the Photon DepthDose Distributions in the ICRU Sphere for a Broad Parallel Beam, A Point Source and an Isotropic Field. National Radiological Protection Board, NRPB 92, Harwell, England.

Ehrlich, M. 1982. "Choice of Conversion Factors to the Shallow and Deep Dose Equivalent for Use in a U.S. Personnel Dosimetry Performance Testing Programme." Radiation Protection Dosimetry, 1(4):271-275.

Gese11, T. F., et al. 1979. A Personnel B-Dosimetry Method for Reducing Energy Dependence. ID0-12090. Idaho National Engineering Laboratory, Idaho Falls, Idaho.

International Commission on Radiation Units and Measurements (ICRU). 1971. Radiation Protection Instrumentation and Its Application. ICRU Report No. 20. ICRU PubTications, Washington, D.C.

International Organization for Standardization (ISO). 1979. $X$ and $\gamma$ Reference Radiations for Calibrating Dosimeters and Dose Ratemeters and for Determining Their Response as a Function of Photon Energy. ISO 4037. UDC 535-34-36:53.089.6. Geneva, Switzerland.

International Organization for Standardization (ISO). 1981. Reference Beta Radiations for Calibrating Dosemeters and Doseratemeters and for Determining Their Response as a Function of Beta Radiation Energy. ISO/DP 6980. Geneva, Switzerland.

Johns, H. E., and J. R. Cunningham. 1978. The Physics of Radiology. Charles C. Thomas Publishing, Springfield, Illinois, p. 322.

Kathren, R. L., F. L. Rising and H. V. Larson. 1971. "K-Fluorescence X-Rays: A Multi-Use Tool for Health Physics." Health Physics, 21:285-293.

Larson, H. V., I. T. Myers and W. C. Roesch. 1954. A Wide Beam Fluorescent $X$-Ray Source. HW-31781, Hanford Atomic Products Operation, Richland, Washington.

McDonald, J. 252, et al. 1983a. Measurements of Gamma-Ray Dose From a Moderated ${ }^{252} \mathrm{Cf}$ Source. NUREG/CR-2975, PNL-4590, Pacific Northwest Laboratory, Richland, Washington.

McDonald, J. C., et al. 1983b. Response Characteristics of Selected Personnel Neutron Dosimeters. PNL-3982, Pacific Northwest Laboratory, Richland, Washington. 
National Council on Radiation Protection and Measurements (NCRP). 1978a. Instrumentation and Monitoring Methods for Radiation Protection. NCRP Report No. 57. NCRP Publications, Washington, D.C.

National Council on Radiation Protection and Measurements (NCRP). $1978 b$. A Handbook of Radioactivity Measurements Procedures. NCRP Report No. 58. NCRP Publications, Washington, D.C.

Nelson, R. F. and A. B. Chilton. 1982. "Depth Doses in Slab Phantom for Low Energy Monoenergetic Photons." Radiation Protection Dosimetry, $1(4): 285-289$.

Plato, P., and G. Hudson. 1980. Performance Testing of Personnel Dosimetry Services: Procedures Manua 1. NUREG/CR-1063. U.S. Nuclear Regulatory Commission, Washington, D.C.

Roberson, P. L., et a1. 1983. Performance Comparisons of Selected Personnel Dosimetry Systems in Use at Department of Energy Facilities. PNL-3983, Pacific Northwest Laboratory, Richland, Washington.

Schwartz, R. B., and C. M. Eisenhauer. 1980. The Design and Construction of a $\mathrm{D}_{2} \mathrm{O}$-Moderated ${ }^{252} \mathrm{Cf}$ Source for Calibrating Neutron Personnel Dosimeters Used at Nuclear Power Reactors. NUREG/CR-1024. U.S. Nuclear Regulatory Commission, Washington, D.C.

Schwartz, R. B., and C. M. Eisenhauer. 1982. Procedures for Calibrating Neutron Personnel Dosimeters. NBS Special Publication 633, U.S. Department of Commerce, National Bureau of Standards, Washington, D.C.

U.S. National Bureau of Standards (NBS). 1981a. Calibration and Related Measurement Services of the National Bureau of Standards. NBS Special Publication 250. U.S. Government Printing Office, Washington, D.C.

U.S. National Bureau of Standards (NBS). 1981b. Requirements for an Effective National Radiation Measurements Program. NBS Special Publication 603. U.S. Government Printing Office, Washington, D.C.

Yoder, R. C., et al. 1979. Confirmation of Conversion Factors Relating Exposure and Dose-Equivalent Index Presented in ANSI N13.11. NUREG/CR-1057, PNL-3219, Pacific Northwest Laboratory, Richland, Washington. 
APPENDIX A

CHOICE OF REFERENCE CALIBRATION SOURCES 
APPENDIX A

\section{CHOICE OF REFERENCE CALIBRATION SOURCES}

Comparisons of occupational exposures reported for various DOE sites are made more difficult by the absence of standard calibration techniques and the use of many dosimeter designs. The establishment of reference calibration techniques will help quantify the effects of differing dosimeter designs and differing occupational environments. The choice of reference sources was based on an intercomparison of dosimeter system performances for DOE laboratories (Roberson et al. 1983) and the American National Standard "Criteria for Testing Personnel Dosimetry Performance", ANSI N13.11-1983 (ANSI 1983). Eleven DOE laboratories participated in the intercomparison to better define presert differences and help develop improved techniques.

The intercomparison of dosimetry system performances was also used to evaluate ANSI N13.11 for use by DOE facilities. It was found that: 1) the number of test categories was incomplete; 2) the performance criteria specified did not achieve the goal of the tests as well as other algorithms; 3 ) the betaparticle category was not sufficiently specified; and 4) the choice of the photon conversion factors was arbitrary. The choice of reference sources was made to be consistent with ANSI N13.11 where practical.

\section{A. 1 CALIBRATION CATEGORIES}

The filtered $x$-ray beams chosen for Table 1 (page 7) are standard NBS techniques (NBS 1981a). The $N 30$ (20 keV) and S60 (36 keV) techniques represent the photon energy region of maximum response for most dosimetry systems. They represent a conservative worst-case test for low-energy photons. The M150 $(70 \mathrm{keV})$ and $\mathrm{H} 150(117 \mathrm{keV})$ techniques are included to extend the test energies above those influenced by the photo-electric effect. The response of dosimetry systems is similar to that of tissue from approximately $200 \mathrm{keV}$ to $2 \mathrm{MeV}$ because of the dominance of the Compton interaction. Tests at these energies 
are represented by the high-energy photon category. Not all of the $x$-ray techniques specified in draft ANSI N13.11 were included because they are not necessary. Nearly monoenergetic sources at 15 to $20 \mathrm{keV}$ and 55 to $65 \mathrm{keV}$ were included specifically for facilities using plutonium. The ${ }^{241}$ Am source (59 keV) may be substituted for the higher energy monoenergetic source.

Most dosimetry systems participating in the DOE performance intercomparison had poor results for low beta-particle energies. The ${ }^{90} \mathrm{Sr} /{ }^{90} \mathrm{Y}$ beta particles are sufficiently energetic to penetrate the popular, thick $\left(230 \mathrm{mg} / \mathrm{cm}^{2}\right) \mathrm{LiF}$ $\mathrm{TL}$ dosimeter chip. This results in a response for ${ }^{90} \mathrm{Sr} /{ }^{90} \mathrm{Y}$ similar to ${ }^{137} \mathrm{Cs}$ for dosimeters that are nearly insensitive to low-energy beta particles. Inclusion of the ${ }^{204} \mathrm{Tl}$ source $(0.76 \mathrm{MeV}$ maximum energy) requires that some attention be given to the lower energies. Reference sources with energies lower than provided by the ${ }^{204} \mathrm{Tl}$ source may be included following improvement in dosimeter technology. The ${ }^{204} \mathrm{Tl}$ source was chosen because of its ease of use and single-beta spectrum.

A natural or depleted-uranium source was added for occupational environments containing uranium. In-phantom dose rates should be measured at $7 \mathrm{mg} / \mathrm{cm}^{2}$ and $100 \mathrm{mg} / \mathrm{cm}^{2}$.

The response ratio of DOE albedo neutron dosimeters for moderated and unmoderated ${ }^{252} \mathrm{Cf}$ irradiations varies from approximately six to twenty (Roberson et a1. 1983). Because the variations are so large, both were chosen for reference sources. The performance evaluation should be performed for the moderated source only, which was chosen to be consistent with ANSI N13.11. Unmoderated ${ }^{252} \mathrm{Cf}$ irradiations can easily be performed as a variation of the moderated ${ }^{252} \mathrm{Cf}$ irradiations. More stringent neutron tests may be included following improvements in neutron dosimeter technology.

\section{A.2 ADDITIONAL SPECIFICATIONS FOR BETA CAL IBRATIONS}

Beta calibrations are affected by source geometry, source filtration, dosimeter irradiation technique, beam calibration technique, and environmental conditions. The standard ANSI N13.1I specifies inherent source filtration, 
phantom size, and source-to-phantom distance for ${ }^{90} \mathrm{Sr} /{ }^{90} \mathrm{Y}$ irradiations but does not adequately address other parameters. Considerable variability in dosimeter response-per-unit delivered dose has been observed among ${ }^{90} \mathrm{Sr} /{ }^{90} \mathrm{Y}$ sources set up to ANSI N13.11 specifications. Additional constraints are necessary to standardize beta calibration techniques for ${ }^{90} \mathrm{Sr} /{ }^{90} \mathrm{Y}$ and ${ }^{204} \mathrm{Tl}$.

We recommend that beta irradiations be standardized according to depthdose characteristics. The specifications for ${ }^{90} \mathrm{Sr} /{ }^{90} \mathrm{Y}$ irradiations are related to mean energy of the source $\left(100 \mathrm{mg} / \mathrm{cm}^{2}\right.$ specification) and Bremsstrahlung production ( $1000 \mathrm{mg} / \mathrm{cm}^{2}$ specification). For ${ }^{204} \mathrm{Tl}$ irradiations, only a specification related to mean energy is given $\left(20 \mathrm{mg} / \mathrm{cm}^{2}\right.$ specification). The depth-dose specifications are intended to take precedence over the source filtration specifications. The intention is to allow the use of source geometries specified in the draft international standard, ISO 6980 (ISO 1981), while maintaining irradiation consistency between laboratories.

\section{A.3 CONVERSION FACTORS FOR EXPOSURE TO DOSE EQUIVALENT FOR PHOTONS}

The exposure-to-dose-equivalent conversion factors for low-energy photons ( $C_{x}$ factors) listed in ANSI N13.11 were derived by Dimbylow and Francis (1979) for the four-element ICRU sphere using Monte-Carlo calculations. For the dosimeter performance tests, the dosimeters are mounted on a slab phantom of methylmethacrylate. Personnel dosimeters are designed to monitor for dose to the tissue of the body on which they are mounted. However, the performance tests require that they monitor for dose to the ICRU sphere while mounted on a slab phantom. This results in the miscalibration of even ideal personnel dosimeters.

The choice of the phantom shape for the specification of $C_{x}$ factors is not arbitrary, as has been argued (Ehrlich 1982). The size and shape of the phantom is important for monitoring low-energy photons because radiation is scattered back to the surface. Backscatter can contribute an additional 40 to $50 \%$ to the dose at the surface for photon energies between $60 \mathrm{keV}$ and $100 \mathrm{keV}$ (Johns and Cunningham 1978). The dosimeter ideally would be able to properly record the level of backscattered radiation and, thus, approximately compensate for fluctuations dependent on the size of the wearer. 
The contribution due to backscattered radiation is different for the slab and spherical phantoms. Nelson and Chilton (1982) used Monte-Carlo calculations to derive the $c_{x}$ factors for the slab geometry with the ICRU fourelement composition. Their results agreed closely with the calculations of Dimbylow and Francis (1979) (spherical geometry) below $50 \mathrm{keV}$, but were 20\% higher between $80 \mathrm{keV}$ and $100 \mathrm{keV}$. This difference accounts for the major discrepancy between the $C_{x}$ factors specified in draft ANSI N13.11 (spherical geometry) and the available direct measurements by Yoder et al. (1979) (slab geometry). Nelson and Chilton (1982) also performed calculations for the tissue-equivalent plastic used by Yoder et al. (1979) for direct measurements of $C_{x}$ factors using the slab geometry. The significant difference between the calculations for the Yoder plastic and the measurements was at energies below $20 \mathrm{keV}$. Nelson and Chilton (1982) attributed this difference to a higher energy contamination in the $k$-fluorescent spectra used by Yoder et al. (1979).

Because of the use of slab phantoms for the reference calibrations, conversion factors for the slab geometry are used. The best available data are by Yoder et al. (1979) and are listed in Table 2. 
APPENDIX B

DERIVATION OF PERFORMANCE CRITERIA 
APPENDIX B

\section{DERIVATION OF PERFORMANCE CRITERIA}

The specifications of performance criteria were based on achievable standards consistent with the goals of health protection. The standards were chosen to be both economically and technologically achievable.

The goals for the accuracy of personnel monitoring were taken from the recommendations of ICRU Report 20 (ICRU 1971) and NCRP Report No. 57 (NCRP $1978 \mathrm{a}$ ), that the accuracy of the maximum dose equivalent be $\pm 30 \%$ near the maximum permissible dose. Due to the small observed variance in dosimeter reading fluctuations for low to high dose equivalents (Roberson et al. 1983), the recommended limit was applied to all levels listed in Table 4 (page 15). The time period over which the accuracy is achieved was not specified by the ICRU or NCRP. In addition, achieving a fixed level of accuracy for all personnel is statistically impossible. The adopted goal was: the annual assignment of dose equivalent should be within $30 \%$ of the conventionally true value for $95 \%$ of the personnel receiving in excess of one-tenth of the maximum permissible dose equivalent.

During the evaluation of a dosimetry system, dosimeters are given a range of doses for each reference calibration point. Performance quotients are calculated for each dosimeter to provide a dose-level independent analysis. The bias (B) is the mean of the performance quotients for a category and the standard deviation $(S)$ is calculated from the performance quotients. For a dosimeter to respond within $30 \%$ of the conventionally true value for a specified confidence interval,

$$
|B|+a \cdot s \leq 0.3
$$

where ' $a$ ' is 1.6 to 2.0 for $95 \%$ of the dosimeters, assuming normally distributed dosimeter responses. The lower value of ' $a$ ' is for a one-sided distribution $(B>0.1)$ and the upper value is for a two-sided distribution $(B \approx 0)$. To 
determine compliance with Equation (B.1) using a small number of test dosimeters, ' $t$ ' statistics should be used (NCRP 1978b). For example, for $95 \%$ confidence interval and fifteen test dosimeters, ' $a$ ' is 1.7 to 2.1 .

If several dosimeter exchanges are used to attain the recommended accuracy and it is assumed that the accumulated dose equivalent is approximately uniformly spread over time, the algorithm is:

$$
|B|+\frac{a}{\sqrt{n}} \cdot s \leq 0.3 \text {. }
$$

For a quarterly exchange rate $(n=4), a / \sqrt{n}=0.8$ to 1.0 to attain the $95 \%$ confidence level. The small increase in 'a' for small groups of test dosimeters has been neglected.

The criterion that

$$
|B|+S \leq 0.3
$$

can represent the implementation of the ICRU and NCRP recommendations on an annual basis for 1) a uniformly-exposed worker using a quarterly dosimeter exchange rate at better than the $95 \%$ confidence level or 2) a worker receiving an unusually large dose on one dosimeter for approximately a $70 \%$ confidence level. These criteria are adequate for the implementation of the guidelines. because the majority of occupational dose is received on a routine schedule.

The implementation of the criteria as written in Equation (B.3) above may require large numbers of dosimeters to measure $|B|$ and $S$ with sufficient precision. Assuming that the dosimeter readings are normally distributed about a single mean, for $95 \%$ of the readings the magnitude of the bias is bounded by:

$$
|B| \leq\left|\bar{P}_{t}\right|+\frac{Z_{0.05}}{\sqrt{n}} \sigma
$$

where $\bar{P}_{t}$ and $\sigma$ are the true mean performance quotient and true standard deviation, $z_{0.05}$ is the probability distribution value that is exceeded for $5 \%$ of the samples, and $n$ is the number of dosimeter readings. For the case 
$\left|\bar{P}_{t}\right|>\sigma_{t}$ a one-sided normal distribution can be used for which $z_{0.05}=$ 1.6. For $\left|P_{t}\right|=0$, the $Z_{0.05}$ value is upper bounded by the two-sided norma 1 distribution $\left(Z_{0.05}=2.0\right)$.

For $95 \%$ of the samples the standard deviation is approximately bound by:

$$
s \leq \sqrt{\frac{x_{0.95}^{2}}{n-1}} \cdot \sigma
$$

using a $x^{2}$ distribution with $(n-1)$ degrees of freedom. Because the uncertainties in $B$ and $S$ are independent for normally distributed data, a close approximation can be obtained for the performance criterion using propagation of. errors:

$$
[|B|+S]_{\max }=\left[\left|P_{t}\right|+\sigma\right]\left\{\left(\frac{Z_{0.05}}{\sqrt{n}}\right)^{2}+\left(\sqrt{\frac{x_{0.95}^{2}}{n-1}}-1\right)^{2}\right\}^{\frac{1}{2}} \sigma
$$

for $95 \%$ of the readings.

The second term on the right-hand side is the amount by which a system that meets the goals for accuracy could fail the performance criteria (Equation B.3) due to a statistical fluctuation of a measurement. This term can be reduced by increasing the number of dosimeters per test. Table B.1 lists the approximate values of the statistical terms as a function of $\sigma$ and the number

\begin{tabular}{|c|c|c|}
\hline$\sigma$ & Number of Dosimeters & $\begin{array}{c}\text { Approximate Value of } \\
\text { Uncertainty Term }\end{array}$ \\
\hline 0.10 & 15 & 0.05 \\
\hline 0.20 & $\begin{array}{l}15 \\
30 \\
60\end{array}$ & $\begin{array}{l}0.10 \\
0.07 \\
0.05\end{array}$ \\
\hline 0.25 & $\begin{array}{r}15 \\
30 \\
60 \\
120\end{array}$ & $\begin{array}{l}0.13 \\
0.09 \\
0.07 \\
0.05\end{array}$ \\
\hline
\end{tabular}

TABLE B.1. 
of dosimeters used per test. For an uncertainty of 5\%, 15, 60, and 120 dosimeters are required for standard deviations of $0.10,0.20$, and 0.25 , respectively. Standard deviations for most beta-particle and photon dosimeters are relatively small $(<0.10)$. Neutron dosimeters are typically greater $(\cong 0.20)$. Only a few of the test categories require as much as a hundred dosimeters to achieve the 0.05 value for the uncertainty term. Therefore, it is reasonable to increase the tolerance level to 0.35 and specify a greater test sample for those dosimeters with large standard deviations (see Section 3.0).

An alternate approach is to perform independent testing for the bias and standard deviation. Then, if the standard deviation is small, the bias can be determined with acceptable precision using relatively few dosimeters. For a large standard deviation, fewer dosimeters are required to test for the standard deviation alone (30 dosimeters at $\sigma=0.25$ ). Unfortunately, an independent test criteria is not readily relatable to a specific health-protection goal. 
APPENDIX C

NEUTRON SCATTER CORRECTIONS 


\section{APPENDIX C}

\section{NEUTRON SCATTER CORRECTIONS}

Neutron room return may be determined empirically or calculated using room scatter formulas. Good agreement has been observed between measured and observed values for albedo dosimeters in a low-scatter geometry (McDonald, et a1. 1983b). However, for smal1 rooms or unusual geometries such as the presence of hydrogenous shielding near the source, considerable error may be present in the scatter calculation. In these cases, the scatter correction should be determined experimentally.

One method of determining the room return is to irradiate dosimeters at several distances along an axis of the beam, noting the deviation in inverse distance squared. A uniform field of scattered neutrons can be assumed if the source is centered in a large room. Calculated dose equivalents based on. dosimeter readings will follow the relationship

$$
\frac{R(r) r^{2}}{(1+a r)}=D_{0}\left(1+S r^{2}\right)
$$

where $R(r)$ is the dosimeter response at distance $r$, ' $a$ ' is the air scatter correction, $D_{0}$ is the "free-field" or unscattered dose equivalent and $S$ is the room return factor in percent per unit distance squared. Air scatter constants based on Monte Carlo calculations are given in Table C.1 (Schwartz and

TABLE C.1. Neutron Air-Scatter Factors

Fractional Increase of Response With Distance From Source, $\left(\mathrm{m}^{-1}\right)$

Dosimeter Bare ${ }^{252} \mathrm{Cf} \quad$ Moderated ${ }^{252} \mathrm{Cf}$

NTA film, polycarbonate track etch

9 in. spherical remmeter

3 in. spherical remmeter

Albedo dosimeter

0.005

0.010

0.009

0.017

0.023

0.011

0.045

Fluence

0.012

0.030

0.040 
Eisenhauer 1982). The constant $S$ is determined for each dosimeter and calibration facility based on the slope and intercept of the regression line. It is suggested that values of $S$ be determined for several directions from the source to check for uniformity of the scattered neutron field.

Formulas for calculating room return are given by Schwartz and Eisenhauer (1982). These are summarized briefly. For reflection from a single surface where the source-to-detector distance is much smaller than the source-tosurface distance:

$$
S=\frac{\alpha}{2}\left(g \frac{\sigma_{r}}{\sigma_{0}}\right) \frac{1}{r^{2}}
$$

where $\alpha$ is the albedo of the reflecting surface, $g$ is the correction for anisotropic detector response, $\sigma_{r} / \sigma_{0}$ is the relative detector response to reflected and source neutrons, and $r$ is the source to surface distance. For concrete and dry soil, a value of 0.54 for $\alpha$ is appropriate. For saturated soil, $\alpha$ should be decreased by $20 \%$. Values of $\left(g \sigma_{r} / \sigma_{0}\right)$ are listed in Table C.2. The single-surface calculation should be employed when the calibration is performed in a metal-walled structure or an outdoor facility. When the source height above the surface is not large compared to the irradiation distance, a more detailed calculation must be followed (Schwartz and Eisenhauer 1982).

For an enclosed calibration facility with concrete or masonary walls:

$$
S=5.6\left(g \frac{\sigma_{r}}{\sigma_{0}}\right) \frac{1}{r_{0}^{2}} \quad\left(\text { bare }{ }^{252} \mathrm{Cf}\right)
$$

or

$$
S=4.5\left(g \frac{{ }^{\sigma} r}{\sigma_{0}}\right) \frac{1}{r_{0}{ }^{2}} \quad \text { (moderated }{ }^{252} \mathrm{Cf} \text { ) }
$$

where $r_{0}$ is the effective radius of the room. The values of $r_{0}{ }^{2}$ is obtained by dividing the room surface area by $4 \pi$. Values of $g\left(\sigma_{r} / \sigma_{0}\right)$ differ for the single scatter surface and enclosed room geometries, as indicated in Table C.2. 
TABLE C.2. Dosimeter Response Factors for Single and Multiple Scatter Surfaces

$g\left(\sigma_{r} / \sigma_{0}\right)$ for Single Scatter Surface

\begin{tabular}{|c|c|c|}
\hline Dosimeter Type & Bare ${ }^{252} \mathrm{Cf}$ & Moderated ${ }^{252} \mathrm{Cf}$ \\
\hline NTA film, polycarbonate track etch & 0.2 & 0.3 \\
\hline Albedo dosimeter & 1.0 & 0.6 \\
\hline 9 in. spherical remmeter & 0.68 & 0.75 \\
\hline 3 in. spherical remmeter & 1.8 & 1.1 \\
\hline \multicolumn{3}{|c|}{$g\left(\sigma_{r} / \sigma_{0}\right)$ for Enclosed Facility } \\
\hline Dosimeter Type & Bare ${ }^{252} \mathrm{Cf}$ & Moderated ${ }^{252} \mathrm{Cf}$ \\
\hline NTA film, polycarbonate track etch & $0.3^{(a)}$ & $0.4^{(a)}$ \\
\hline Albedo dosimeter & 2.1 & 0.58 \\
\hline 9 in. spherical remmeter & 0.52 & 0.85 \\
\hline 3 in. spherical remmeter & 2.9 & 1.4 \\
\hline
\end{tabular}

(a) Estimated by Schwartz and Eisenhauer (1982).

The total scatter correction is equal to $1+a r+s r^{2}$. An additional factor may be added to account for scattering from source encapsulation and supporting structures. This correction usually is small and must be determined on a case-by-case basis. When a calibration is performed, the delivered dose equivalent is considered to be the product of the free-field dose equivalent (calculated from source emission rate) and the scatter factor. 

APPENDIX D

PEER REVIEW 


\section{APPENDIX D}

\section{PEER REVIEW}

This document was reviewed by technical representatives of most major DOE facilities. Several comments were incorporated. These were:

- The addition of the 15 to $20 \mathrm{keV}$ nearly monoenergetic photon source for plutonium environments.

- The addition of the uranium slab calibration source. Other comments were:

- Changes should be made to the accident categories: reduction in frequency of testing; reduction in number of dosimeters; or perhaps an initial testing followed by an annual assessment of procedures. The high dose levels required in the accident categories result in permanent damage to TLD materials, which results in these TLD materials being eliminated from further use. This damage is manifest in two ways: a high residual signal is left in the TLD material, which cannot be removed through normal readout procedures; and high dose levels result in increased TLD sensitivity even if the TLD material can be annealed at elevated temperatures.

- One dosimeter is not the best for all situations. At many sites two or more dosimeters may be used. It is important for a processor to clearly classify the dosimeter system tested to indicate that the dosimeter is in compliance with the guidelines only for a given environment. In the case of multiple dosimeters, all dosimetry configurations used should be tested.

- It is recommended that all depths be looked at with each test. 


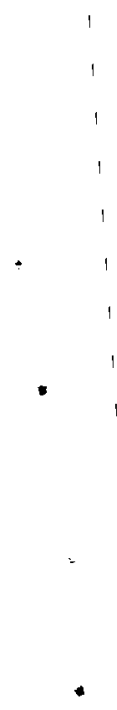




\section{DISTRIBUTION}

No. of

Copies

OFFSITE

5

$$
\begin{aligned}
& \text { E. J. Vallario } \\
& \text { Senior Health Physicist } \\
& \text { DOE Division of Operational and } \\
& \text { Environmental Safety } \\
& \text { Washington, DC } 20545 \\
& \text { J. P. Cusimano } \\
& \text { RESL-CF } 6980 \\
& \text { U.S. Department of Energy } \\
& \text { 550 Second Street } \\
& \text { Idaho Fal1s, ID } 83401
\end{aligned}
$$

27 DOE Technical Information Center

E. H. Dolecek

Argonne National Laboratory

OHS/HP B1dg. 14

9700 S. Cass Avenue

Argonne, IL 60439

L. Phillips

Brookhaven National Laboratory

B7dg. 535A

Upton, NY 11973

C. Swezey

Brookhaven National Laboratory

Bldg. 535A

Upton, NY 11973

R. M. Hall

735-A

Savannah River Plant

E. I. DuPont deNemours \& Company

Aiken, SC 29801

J. H. Elliott

Lawrence Livermore National Laboratory

P.0. Box $5505 \quad L-383$

Livermore, CA 94550
No. of

Copies

T. J. Powell

Lawrence Livermore National Laboratory

P.0. Box $5505 \quad L-383$

Livermore, CA 94550

J. R. Cortez

Los Alamos National Laboratory

Box 1663, MS 692

Los Alamos, NM 87545

J. H. P. Lawrence

Group $H-1$, MS-401

Los Alamos National Laboratory

Los Alamos, NM 87545

E. Storm

Los Alamos National Laboratory

Box 1663 MS-692

Los Alamos, NM 87545

S. L. Crain

Monsanto Research

Mound Facility

Miamisburg, OH 45432

R. B. Schwartz

Bldg. 235

National Bureau of Standards

Washington, DC 20234

R. E. Alexander

Pantex Plant

P.0. Box 30020

Amari110, TX 79177

B. P. Smith

Reynolds Electic \& Engineering Co., Inc.

P.0. Box 14400 MS-708

Las Vegas, NV 89114 
No. of

Copies

I. J. Wells

Reynolds Electric \& Engineering Co. , Inc.

P.0. Box 14400 MS-708

Las Vegas, NV 89114

R. B. Falk

Rockwell International

Rocky Flats Plant

P.0. Box 464

Golden, C0 80401

R. C. Yoder

R. S. Landauer, Jr. and Co.

Glenwood Science Park

Glenwood, IL 60425

D. J. Thompson

Radiation Dosimetry

Division 3313

Sandia National Laboratories

P. 0. Box 5800

Albuquerque, NM 87185

K. L. (Holbrook) Jones

265 El Dorado Blvd.

No. 713

Webster, TX 77598
No. of

Copies

ONSITE

DOE Richland Operations Office

H. E. Ransom/ P. K. Clark

30

Pacific Northwest Laboratory

W. J. Bair

T. H. Essig

L. G. Faust

J. J. Fix

R. A. Fox

R. T. Hadley

W. A. Glass

G. R. Hoenes

R. T. Hogan

C. D. Hooker

J. C. McDonald

J. L. Pappin

P. L. Roberson (10)

J. M. Selby

Technical Information (5)

Publishing Coordination (2) 